\title{
The Study of Abrasive Water Jet Cutting Front Development using a Two-Dimensional Cellular Automata Model
}

\author{
Marko Jerman ${ }^{1, *}$ - Joško Valentinčičl - Andrej Lebar1,2 - Henri Orbanić1 \\ 1 University of Ljubljana, Faculty of Mechanical Engineering, Slovenia \\ 2 University of Ljubljana, Faculty of Health Sciences, Slovenia
}

\begin{abstract}
In this paper, the cutting front development during abrasive water jet (AWJ) cutting is studied using a two-dimensional cellular automata (CA) model, hence the striation formation phenomenon is studied indirectly. To calculate the shape of the cutting front, the CA model uses the following inputs: cutting velocity, AWJ intensity and material type. The cutting process is described by simplified material removal and AWJ propagation models in the form of CA rules. The rules encompass AWJ ability to erode the workpiece material and, inversely, the workpiece material's resistance to the erosion process. The proposed CA model is validated by checking the trend of the cutting front development at various input parameters. The simulation results are in good agreement with experimentally obtained trends and thus confirm the proper setup of CA rules. This gives a better insight into the AWJ cutting mechanism.

Keywords: abrasive water jet, cutting front, striation formation, cellular automata, simulation

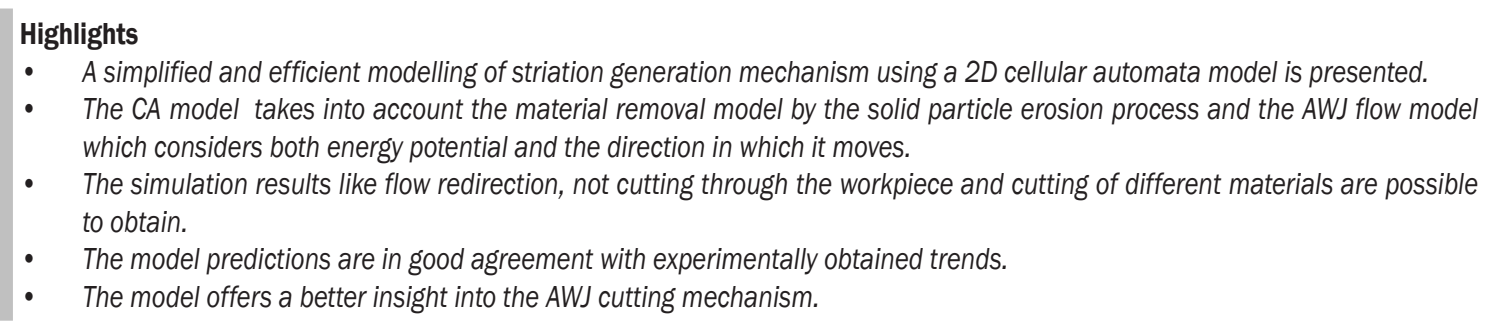

\section{INTRODUCTION}

Abrasive water jet (AWJ) machining is a nonconventional machining process, which uses a highspeed water jet to accelerate hard abrasive grains in order to remove workpiece material. The process is mostly used for 2D and 3D cutting. In general, it can be used to cut any kind of material, regardless of its composition, structure, hardness or other physical properties. Many new materials in use today are impossible or very difficult to machine with other processes.

Typically, the surface cut by AWJ is striated. The striations are curved opposite to the cutting direction. The curvature and thickness mostly depend on the workpiece material, AWJ cross section, intensity and cutting velocity. Removal processes, which include solid particle erosion, e.g. AWJ machining, are very complex and thus difficult to describe theoretically [1]. Consequently, several numerical models have been developed to simulate the AWJ cutting process and to better understand it. Still, the main challenge is to develop a good striation formation model and thus try to find a solution which would reduce this phenomenon.

Several researchers have developed numerical models of AWJ cutting by recognizing the importance of describing the trajectory of abrasive grains and then calculating the material removal. The final results produced either $2 \mathrm{D}$ cutting front shapes or $3 \mathrm{D}$ cut surfaces, depending on the model complexity:

Fukunishi et al. [2] and [3] have developed a numerical model based on multiple jet impacts and Bitter's erosion theory [4] and [5]. A similar approach was used by Vikram and Babu [6] and El Tobgy et al. [7] who used a different material erosion model. Yong and Kovacevic [8] used a numerical method of memory cells to record the depth achieved by erosion of each abrasive grain. Ditzinger et al. [9] analyzed the formation of surface structures during the cutting process. Lebar [10] and Lebar and Junkar [11] developed the unit event model for generating the topography of the surface made by AWJ cutting. Deam et al. [12] developed a two-part two-dimensional model which predicts the shape of the cutting front. Zaki et al. [13] coupled a Computational Fluid Dynamics (CFD) solver, which simulates the dynamics of the AWJ, and a simplified material erosion. Some recent research has dealt with numerical simulations in such a way that LS-DYNA software was used to couple the AWJ flow model and material removal model [14] and [15].

The reviewed models show that extensive work has been performed in this area, but often the results 
are limited to one material or a limited number of process parameter combinations. The cellular automata (CA) approach presented in this paper can, on the other hand, give a better insight into the studied process. CA have been used to model various processes found in nature and technology. They can be found in medicine for modelling the spread of virus infections [16], the growth of cancerous tissue [17] or image processing [18]. Other uses involve modelling of various diffusion processes, forest fires [19] and traffic [20]. In the area of mechanical engineering, CA have been used for modelling the structural changes in materials [21], modelling of etching process in integrated circuit manufacturing process [22] and fluid mechanics [23]. CA are extensively used in geology for modelling land erosion [24] and river meandering [25]. A similar process called solid particle erosion is the basic material removal mechanism in AWJ machining. The usage of CA for modelling of the AWJ machining process was first reported in Orbanic and Junkar's research paper [26].

In this paper, a significantly improved version of a previous two-dimensional CA model of AWJ cutting developed by Orbanic and Junkar [26] is presented, which simulates the development of the cutting front as it depends on the process parameters. The model allows a simple description of a complex process on a micro level, such as AWJ flow and material removal process for different types of material, and then quickly produces results for the macro level, thus allowing to quickly check different hypotheses. Additionally, the CA method is relatively simple to implement into computer code and offers vast parallelisation capabilities, which drastically shorten the computational times.

The main goal of the paper is to check the hypothesis described in the previous work performed by one of the authors [27], stating that the striation formation process is influenced by the shape of the cutting front. Based on it, special concern is given to the material model for various types of workpiece materials and the influence of the cutting front shape on the direction of AWJ flow and the direction of material removal. In the end the simulation was compared with actual experiments in order to confirm the proper functioning of the model.

\section{NUMERICAL MODEL}

The CA represent an idealization of a physical system, in which space and time are discrete and the physical quantities take only a finite set of values [28]. They consist of equally distributed arrays, which can be of unlimited range. Each element of the array is characterized by a value of a certain physical quantity. This physical quantity, as a collection of all states in cells at a certain time, represents the global state of the CA. On the other hand, the value of the physical quantity in each cell represents a local state of the CA. Each cell in the CA can only interact with those cells that are in its neighbourhood. As a consequence, the cells in the CA are not able to communicate on a global level with other cells [29].

\subsection{CA AWJ Cutting Model Definition}

When using CA the modelled space of the process (AWJ cutting) has to be digitalized i.e. divided into an array of equal sized cells. The procedure is schematically shown in Fig. 1 where three characteristic areas define the states of CA: empty space - ES, abrasive water jet - AWJ and workpiece material - MAT.
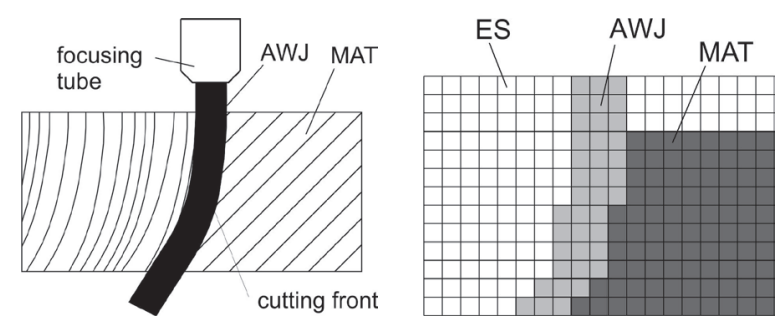

Fig. 1. The digitization of the AWJ cutting process with three characteristic areas

The difference between this and the base model previously described [26] is the reduced number of states. In this model, ES is a part of the AWJ state. This state represents the intensity of the AWJ or its ability to remove material. It is defined by two parameters:

- The first parameter is the intensity of AWJ $\left(A_{\text {awj }}\right)$, which describes the kinetic energy of the jet, thus it depends on the process parameters, such as water pressure, water and abrasive mass flow rate, type and size of abrasive grains and geometry of the cutting head. Since the generation process of AWJ is very complex, it is currently not included in the model.

- The second parameter is the jet flow direction vector which describes the direction of AWJ operation. The empty space, which is part of the AWJ state, represents the state with low intensity and undefined flow direction. The MAT state is defined as a material removal resistance. It is represented by the parameter $M_{\text {mat }}$. The higher 
the value of the parameter, the more time is required to remove the whole cell of material. The parameter $M_{\text {mat }}$ is defined according to the machinability number $N_{\mathrm{m}}$ as:

$$
M_{\mathrm{mat}}=10000 / N_{\mathrm{m}} \text {. }
$$

The machinability number was introduced by Zeng and Kim [30] and [31]. In their semi-empiric model of AWJ cutting $N_{\mathrm{m}}$ represents a unique material property while cutting with AWJ. It is a simplified machining parameter of material erosion resistance, which was defined by authors in their theoretical model for calculating the depth of cut. Because $N_{\mathrm{m}}$ decreases with harder to machine materials, the Eq. (1) uses an inverse form. Currently, the $N_{\mathrm{m}}$ goes up to 15,000 [32] for foams which in practice are cut with pure water jet; therefore, a value of 10,000 was chosen as a limit at which the material can be cut without an abrasive.

The quantity of the removed material is calculated according to the intensity and impact angle of AWJ flow acting against a material cell with certain material resistance. At the same time the intensity of the AWJ in the neighbouring cells, which participated in the process of material removal, is reduced. After the new shape of the cutting front is determined, the normal vector at each point of the front is determined. This vector is later used for calculation of flow direction change for each part of the AWJ because of its contact with the cutting front. The contact was modelled as a specular reflection, thus by using the appropriate equation the new flow direction is calculated.

The AWJ flow in each cell is described by the intensity and direction value. The flow is considered to be infinite, and the intensity changes according to the flow direction in the cell, the intensity of the neighbouring cells and according to the energy spent for material removal. The previously mentioned definition of low AWJ intensity inside empty space cells was used in order to simulate the free flow of the jet in an empty space.

The whole area of CA is divided into an array of $n \times m$ cells. Rows are denoted by a variable $i$ : the top row has a value 1 and the bottom row has a value $n$. Columns are denoted by the variable $j$ : the left column has a value 1 and the right column has a value $m$.

In this space nine matrices are defined. The first matrix B, also called the matrix of states, represents the global space of CA. The values in this matrix can be 1 if the state is workpiece material or 2 otherwise (AWJ or empty space). Therefore, matrix $\mathbf{B}$ represents an instant picture of the process cycle. The border between the two states represents the cutting front. After initialization, all cells in matrix $\mathbf{B}$ have the state 1 except the cells in the first row $(i=1)$ for moving the AWJ source, which is described by matrix $\mathbf{C}$, and initial columns (in our case $j=\{1,2,3\}$ as described latter).

Matrix A contains values of AWJ intensity for each cell, and matrix $\mathbf{M}$ contains the values of material removal resistance. Matrices $\mathbf{N}_{\mathrm{x}}$ and $\mathbf{N}_{\mathrm{y}}$ contain $x$ and $y$ components of the normal vector of the cutting front for each cell. Matrices $\mathbf{S}_{\mathrm{x}}$ and $\mathbf{S}_{\mathrm{y}}$ contain $x$ and $y$ components of the AWJ flow direction vector for each cell. The last two matrices $\Phi$ and $\mathbf{R}$ contain the inclination of the cutting front and material removal coefficients for each cell, which are calculated according to the cutting front inclination. It should be noted that the values for matrices $\mathbf{N}_{\mathrm{x}}, \mathbf{N}_{\mathrm{y}}, \Phi$ and $\mathbf{R}$ are 0 in cells which do not lie on the cutting front.

Initialization of matrices $\mathbf{A}$ and $\mathbf{M}$ are performed according to the Table 1. For the cells in state 2 (matrix B), the initial values of matrix $\mathbf{A}$ where the AWJ is situated are equal to $A_{\text {awj }}$ and value 1 elsewhere. The latter value is needed for the purpose of AWJ intensity redistribution calculation as presented in the concept description.

Table 1. Initialization of matrices $\mathbf{A}$ and $\mathbf{M}$ depends on the values in matrix $\mathbf{B}$

\begin{tabular}{ccc}
\hline $\mathbf{B}(i, j)$ & $\mathbf{A}(i, j)$ & $\mathbf{M}(i, j)$ \\
\hline 1 & 0 & $M_{\text {mat }}$ \\
\hline 2 & 1 or $A_{\text {awj }}$ & 0 \\
\hline
\end{tabular}

A very important part of the CA is the definition of the AWJ source. The source is represented by a onedimensional $\mathbf{C}$ array, which contains the information about jet diameter, the initial value of the AWJ intensity and its distribution. The flow vector of the source is directed downwards i.e. in $-y$ direction. The jet's movement is simulated by moving matrix $\mathbf{C}$ in the first row of the CA. Matrix $\mathbf{C}$ elements have the initial $A$ awj value while the rest of the first row cells have value 1. Movement of the matrix $\mathbf{C}$ is defined by the number of simulation cycles $t_{\mathrm{c}}$ needed to move the matrix one cell forward, i.e. $j+1$. Thus it is defined as the inverse value of the simulated cutting velocity $v_{\mathrm{c}}$ in unit cells per cycle (Eq. (2)).

$$
t_{c}=v_{c}^{(-1)} \text {. }
$$

For calculations in the CA, the von Neumann neighbourhood with radius one (Fig. 2) was chosen. 


\subsection{Numerical Calculation Procedure}

In the numerical simulation first the $\mathrm{CA}$ area is divided on an $n \times m$ matrix of identical square cells. Initial conditions are imposed by changing the states of specified CA cells and defining initial values for material resistance in $\mathbf{M}$ and initial values for AWJ intensity in A. The first row is reserved for jet movement, i.e. movement of subarray C. After initialization, the simulation starts. On each cycle the condition for jet movement according to number $t_{\mathrm{c}}$ is checked. Each time it is fulfilled the jet moves forward by one cell, otherwise the jet stays in place. Then the CA rules are checked. The simulation continues until the total number of time steps is equal to $T$ after which the simulation stops. The global states of the CA are recorded during each time step, and the shape of the cutting front is determined and recorded.

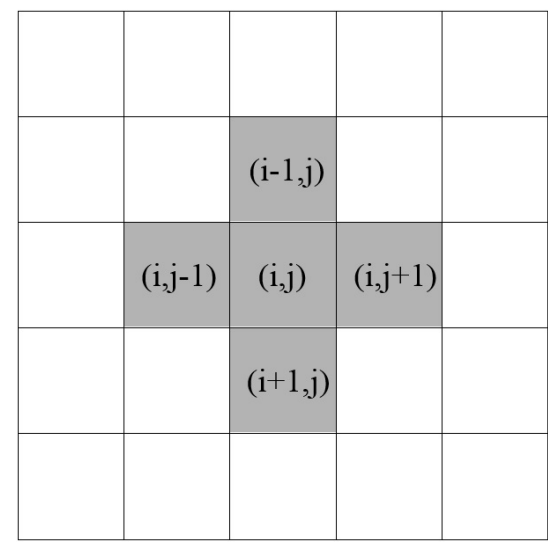

Fig. 2. The von Neumann neighbourhood of the (i, j) cell comprised 5 grey cells
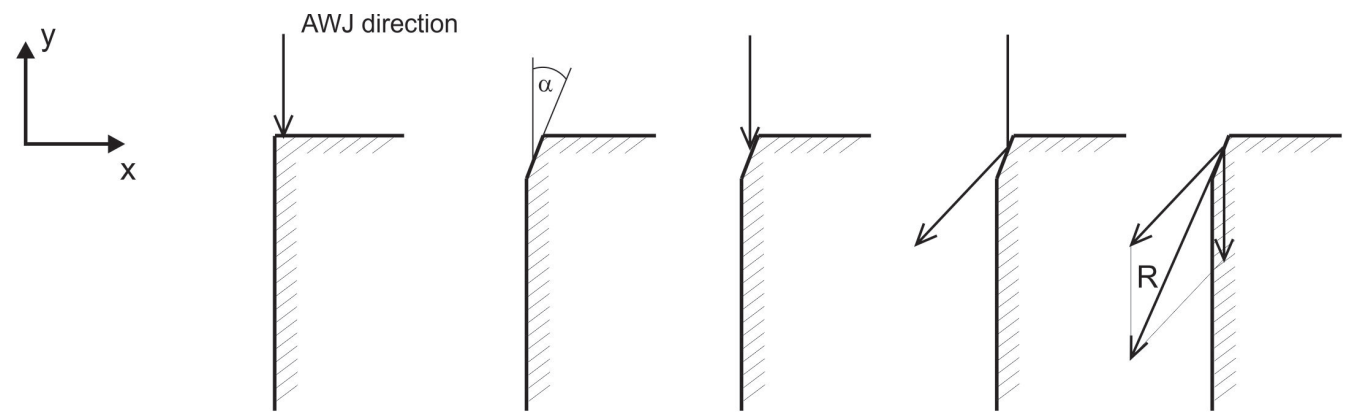

\begin{tabular}{|l|}
\hline Initial condition: \\
$-A_{\text {awj }}$ \\
$-M_{\text {mat }}$ \\
$-V$ \\
$-\vec{S}$ \\
\hline
\end{tabular}
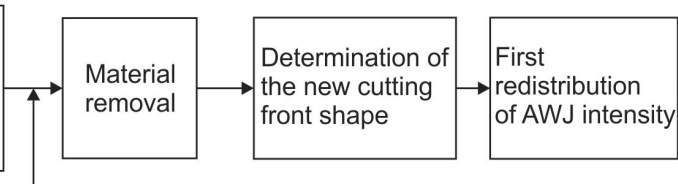

Second redistribution and calculation of the new AWJ flow direction

Fig. 3. The five phase sequence during a single cycle of the $C A$ 
at $t, R_{i-1, j}^{t}, R_{i+1, j}^{t}, R_{i, j-1}^{t}$ and $R_{i, j+1}^{t}$ are material removal coefficients at time $t$. During the calculation of material removal, only cells with AWJ intensity higher than 1 can participate, thus the signum function $\operatorname{sgn}(x)$ in combination with the floor function $[x]$ is used. The floor function first rounds AWJ intensity downwards in cells $A_{i-1, j}^{t}, A_{i+1, j}^{t}, A_{i, j-1}^{t}$ and $A_{i, j+1}^{t}$ in such a way that values less than 1 are rounded to 0 . Next, the signum function is used. For a real number $x$ it is defined as follows:

$$
\operatorname{sgn}(x)=\left\{\begin{array}{ccc}
-1 & \text { if } & x<0 \\
0 & \text { if } & x=0, \\
1 & \text { if } & x>0 .
\end{array}\right.
$$

Therefore, whole parts of Eq. (3) can be discarded if AWJ intensity in neighbouring cells is lower than 1. If $M_{i, j}^{t+1}<0$, the value of $M_{i, j}^{t+1}$ is switched to 0 in order to prevent negative material resistance. A similar approach was used by Karafyllidis and Thanailakis [22]. When $M_{i, j}^{t+1}=0$, the material is removed and the cell $B_{i, j}^{t+1}$ changes from state 1 to state 2 which means that the cell is filled by the AWJ flow.

After the material removal rule is performed in the given cell $(i, j)$, the AWJ intensity is proportionally reduced in the neighbouring cells depending on the participation of each cell in the material removal process according to the following equations:

$$
\begin{aligned}
& A_{i-1, j}^{t+1,1}=A_{i-1, j}^{t} \cdot\left(1-R_{i-1, j}^{t}\right), \\
& A_{i+1, j}^{t+1,1}=A_{i+1, j}^{t} \cdot\left(1-R_{i+1, j}^{t}\right), \\
& A_{i, j+1}^{t+1,1}=A_{i, j+1}^{t} \cdot\left(1-R_{i, j+1}^{t}\right), \\
& A_{i, j-1}^{t+1,1}=A_{i, j-1}^{t} \cdot\left(1-R_{i, j-1}^{t}\right),
\end{aligned}
$$

where $A_{i-1, j}^{t+1,1}, A_{i+1, j}^{t+1,1}, A_{i, j+1}^{t+1,1}$ and $A_{i, j-1}^{t+1,1}$ are AWJ intensities in the neighbouring cells in the first part of the CA cycle.

The second phase of the CA cycle determines the new shape of the cutting front and calculates the normal vectors on the cutting front. The matrix of material removal coefficients $\mathbf{R}$ and the new direction of AWJ flow after impact with the cutting front are calculated. The cutting front shape is obtained from the matrix of states $\mathbf{B}$ by determining the position of material cells at the border with AWJ cells.

Before the normal vector for each point on the cutting front is determined, a tangent vector of the curve $\vec{r}$ has to be calculated. This is done by subtracting position vectors of neighbouring points on the cutting front. To simplify further calculations the vector is normalized into $\hat{r}$. In order to obtain the normal vector $\vec{n}$, vector needs to be rotated around axis $z$ for an angle duration of $-90^{\circ}$ as shown in Fig. 4 . The rotation around the $z$-axis is performed by using rotation matrix $\mathbf{T}$ :

$$
\begin{aligned}
\hat{n}=\mathbf{T} \cdot \hat{r} & =\left[\begin{array}{ccc}
\cos \left(-\frac{\pi}{2}\right) & -\sin \left(-\frac{\pi}{2}\right) & 0 \\
\sin \left(-\frac{\pi}{2}\right) & \cos \left(-\frac{\pi}{2}\right) & 0 \\
0 & 0 & 1
\end{array}\right] \cdot\left[\begin{array}{c}
r_{x} \\
r_{y} \\
0
\end{array}\right]= \\
& =\left[\begin{array}{ccc}
0 & 1 & 0 \\
-1 & 0 & 0 \\
0 & 0 & 1
\end{array}\right] \cdot\left[\begin{array}{c}
r_{x} \\
r_{y} \\
0
\end{array}\right]=\left[\begin{array}{c}
r_{y} \\
-r_{x} \\
0
\end{array}\right] .
\end{aligned}
$$

The calculated normal vectors have to be entered into two matrices $\mathbf{N}_{\mathrm{x}}$ and $\mathbf{N}_{\mathrm{y}}$ where each one contains the $x$ and $y$ components of normal vectors. In this way each normal vector on the cutting front is transferred to the corresponding cell of the CA. Next, the impact angle $\varphi$ is calculated for each cell on the cutting front (Eq. 10) and, based on this, the necessary material removal coefficients. Since all matrices of flow direction and normal vector components are normalized, it follows that:

$$
\cos (\Phi)=\frac{\mathbf{N}_{\mathrm{x}} \cdot \mathbf{S}_{\mathrm{x}}+\mathbf{N}_{\mathrm{y}} \cdot \mathbf{S}_{\mathrm{y}}}{1 \cdot 1},
$$

where $\boldsymbol{\Phi}$ is the matrix of the cutting front inclination. The value of matrix $\boldsymbol{\Phi}$ in cells which are not on the cutting front is equal to 0 .

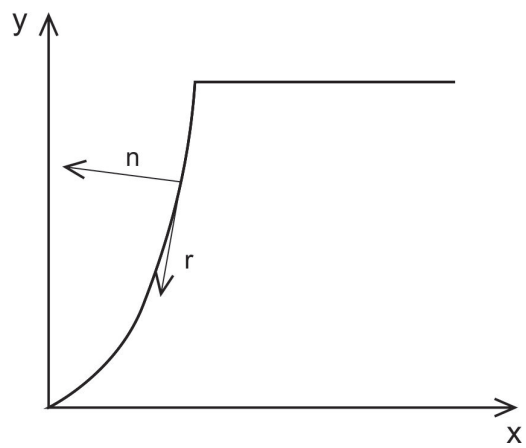

Fig. 4. Normal vector $\vec{n}$ is perpendicular to the tangent vector $\vec{r}$ in the clockwise direction

The matrix of material removal coefficients $\mathbf{R}$ is calculated by using the polynomial of $4^{\text {th }}$ degree, which 
was experimentally determined by Lebar [10] and by Lebar and Junkar [11] for solid particle erosion of aluminium by AWJ. It describes the material removal rate dependence on the impact angle of the AWJ. For this research, the polynomial was normalized in order to simulate cutting of ductile materials:

$$
\begin{aligned}
\mathbf{R} & =5.6 \cdot 10^{-8} \cdot \Phi^{4}-4.5 \cdot 10^{-6} \cdot \Phi^{3}- \\
& -4.8 \cdot 10^{-4} \cdot \Phi^{2}+4.7 \cdot 10^{-2} \cdot \Phi+1.8 \cdot 10^{-3} .
\end{aligned}
$$

This equation can also be used for other materials (ductile and brittle materials that under certain conditions show ductile behaviour during solid particle erosion), since only the relation between material removal and impact angle is required for CA calculations. According to several publications [33] to [35], this can occur at lower impact angles (up to $30^{\circ}$ ) and smaller sizes of abrasive grains. During many practical examples where solid particle erosion appears (such as AWJ cutting), lower impact angles are usually predominant [33]. In this paper, cutting of soda lime glass, which is grouped under brittle materials, was simulated. On the other hand, its machinability by AWJ is higher than most of the metals which show ductile behaviour.

The third phase of the cycle is the first redistribution of the AWJ intensity in matrix $\mathbf{A}$. Redistribution in the cell $(i, j)$ is calculated by the weighted average, where the weights $w$ are determined with regard to the flow direction vector in the cell. Before the redistribution, a change of direction vectors in the cell needs to be calculated due to the mutual interaction between cells with state 2 . This simulates the changes inside the flow itself. Applying Eqs. (12) to (14), the resultant of direction vectors in the neighbourhood of the cell $(i, j)$ is calculated, and then normalization of the resultant vector by Eqs. (15) and (16) is performed:

$$
\begin{gathered}
S_{x(i, j)}^{t+1,3}=S_{x(i, j)}^{t}+S_{x(i-1, j)}^{t}+S_{x(i+1, j)}^{t}+ \\
+S_{x(i, j-1)}^{t}+S_{x(i, j+1)}^{t}, \\
S_{y(i, j)}^{t+1,3}=S_{y(i, j)}^{t}+S_{y(i-1, j)}^{t}+S_{y(i+1, j)}^{t}+ \\
+S_{y(i, j-1)}^{t}+S_{y(i, j+1)}^{t}, \\
\left|S_{y(i, j)}^{t+1,3}\right|=\sqrt{\left(S_{x(i, j)}^{t+1,3}\right)^{2}+\left(S_{y(i, j)}^{t+1,3}\right)^{2}}, \\
\hat{S}_{x(i, j)}^{t+1,3}=\frac{S_{x(i, j)}^{t+1,3}}{\left|S_{i, j}^{t+1,3}\right|},
\end{gathered}
$$

$$
\hat{S}_{y(i, j)}^{t+1,3}=\frac{S_{y(i, j)}^{t+1,3}}{\left|S_{i, j}^{t+1,3}\right|} .
$$

The weights for neighbouring cells are calculated by Eqs. (17) to (20):

$$
\begin{gathered}
w_{i-1, j}=\left|\hat{S}_{y(i, j)}^{t+1,3}\right| \cdot\left(-1+\operatorname{sgn}\left(\hat{S}_{y(i, j)}^{t+1,3}\right)\left(-\frac{1}{2}\right),\right. \\
w_{i, j-1}=\left|\hat{S}_{x(i, j)}^{t+1,3}\right| \cdot\left(1+\operatorname{sgn}\left(\hat{S}_{x(i, j)}^{t+1,3}\right)\left(\frac{1}{2}\right),\right. \\
w_{i, j+1}=\left|\hat{S}_{x(i, j)}^{t+1,3}\right| \cdot\left(-1+\operatorname{sgn}\left(\hat{S}_{x(i, j)}^{t+1,3}\right)\left(-\frac{1}{2}\right),\right. \\
w_{i+1, j}=\left|\hat{S}_{y(i, j)}^{t+1,3}\right| \cdot\left(1+\operatorname{sgn}\left(\hat{S}_{y(i, j)}^{t+1,3}\right)\left(\frac{1}{2}\right) .\right.
\end{gathered}
$$

When calculating the weights, only two weights are considered per each cell while the other two are equal to zero. This is the consequence of the following rule: the AWJ flow is directed regarding the components $x$ and $y$ of the flow direction vector of the $(i, j)$ cell. The new AWJ intensity for the $(i, j)$ cell in the third part of the cycle is calculated by Eq. (21):

$$
A_{i, j}^{t+1,3}=\frac{\left[\begin{array}{r}
A_{i-1, j}^{t+1,1} \\
A_{i, j-1}^{t+1,1} \\
A_{i, j+1}^{t+1,1} \\
A_{i+1, j}^{t+1,1}
\end{array}\right] \cdot\left[\begin{array}{l}
w_{i-1, j} \\
w_{i, j-1} \\
w_{i, j+1} \\
w_{i+1, j}
\end{array}\right]}{w_{i-1, j}+w_{i, j-1}+w_{i, j+1}+w_{i+1, j}} .
$$

This procedure is repeated for every cell in the CA matrix.

The fourth phase of the cycle calculates the change of AWJ flow direction due to the flow contact with the cutting front. It was assumed that the interaction is similar to the specular reflection, which means the flow direction vector of the cell $(i, j)$ has to be mirrored around the normal vector in the same cell. Therefore, a transformation matrix for calculating reflection $\mathbf{Z}$ was defined according to the data in existing research [36]. The matrix for the three dimensional Cartesian space is defined according to the vector around which the mirroring is being performed:

$$
\mathbf{Z}=\left[\begin{array}{ccc}
-\mathbf{N}_{\mathrm{x}}^{2}+\mathbf{N}_{\mathrm{y}}^{2}+\mathbf{N}_{\mathrm{z}}^{2} & -2 \cdot \mathbf{N}_{\mathrm{x}} \cdot \mathbf{N}_{\mathrm{y}} & -2 \cdot \mathbf{N}_{\mathrm{x}} \cdot \mathbf{N}_{\mathrm{z}} \\
-2 \cdot \mathbf{N}_{\mathrm{y}} \cdot \mathbf{N}_{\mathrm{x}} & \mathbf{N}_{\mathrm{x}}^{2}-\mathbf{N}_{\mathrm{y}}^{2}+\mathbf{N}_{\mathrm{z}}^{2} & -2 \cdot \mathbf{N}_{\mathrm{y}} \cdot \mathbf{N}_{\mathrm{z}} \\
-2 \cdot \mathbf{N}_{\mathrm{z}} \cdot \mathbf{N}_{\mathrm{x}} & -2 \cdot \mathbf{N}_{\mathrm{z}} \cdot \mathbf{N}_{\mathrm{y}} & \mathbf{N}_{\mathrm{x}}^{2}+\mathbf{N}_{\mathrm{y}}^{2}-\mathbf{N}_{\mathbf{z}}^{2}
\end{array}\right] .
$$


Thus, the equation for mirroring the flow direction vectors in two dimensions is:

$$
\begin{aligned}
& {\left[\begin{array}{l}
\hat{\mathbf{S}}_{\mathrm{X}}^{t+1,4} \\
\hat{\mathbf{S}}_{\mathrm{y}}^{t+1,4}
\end{array}\right]=} \\
& =\left[\begin{array}{ccc}
-\mathbf{N}_{\mathrm{x}}^{2}+\mathbf{N}_{\mathrm{y}}^{2} & -2 \cdot \mathbf{N}_{\mathrm{x}} \cdot \mathbf{N}_{\mathrm{y}} & \hat{\mathbf{S}}_{\mathrm{x}}^{t+1,3} \cdot\left(1-\left|\operatorname{sgn}\left(\mathbf{N}_{\mathrm{x}}\right)\right|\right) \\
-2 \cdot \mathbf{N}_{\mathrm{y}} \cdot \mathbf{N}_{\mathrm{x}} & -\mathbf{N}_{\mathrm{y}}^{2}+\mathbf{N}_{\mathrm{x}}^{2} & \hat{\mathbf{S}}_{\mathrm{y}}^{t+1,3} \cdot\left(1-\left|\operatorname{sgn}\left(\mathbf{N}_{\mathrm{y}}\right)\right|\right)
\end{array}\right] . \\
& \cdot\left[\begin{array}{l}
\hat{\mathbf{S}}_{\mathrm{x}}^{t+1,3} \\
\hat{\mathbf{S}}_{\mathrm{y}}^{t+1,3} \\
1
\end{array}\right] .
\end{aligned}
$$

This rule is performed only in cells which are near the cutting front and where the normal vector components in those cells have nonzero values. In this way, the change of the AWJ flow direction vector to $(0,0)$ is prevented in cells not at the cutting front.

The fifth and last phase of the CA cycle contains the second redistribution of the AWJ intensity which follows the jet deflection. This part is similar to the third phase but is necessary for calculation of resulting flow direction vectors and redistribution of the AWJ intensity resulting from the interaction between AWJ cells, which changed flow direction due to deflection from the cutting front, and those which did not. The calculations for this part are performed with the same set of equations as in part three (Eqs. (12) to (21)).

\section{SIMULATION SETUP}

The CA space is divided into $55 \times 150$ cells, thus all the matrices except matrix $\mathbf{C}$ are of this size. The AWJ source is 3 cells wide, bringing the first three columns of matrix B to state 2. The rest of the cells are taken as the workpiece material, so they are in state 1 . Therefore, the dimension of the workpiece is $54 \times 147$ cells. The variable input parameters, which have to be set before the simulation start, are material resistance $M_{\text {mat }}$, AWJ source intensity $A_{\text {awj }}$ and simulation cutting velocity $v_{\mathrm{c}}$. It was also decided to use a uniform distribution of the AWJ intensity at the source; therefore, all three cells have the same value. The initial value of material removal resistance $M$ mat is calculated with Eq. (1).

The CA simulation was programmed using the MATLAB numerical computing environment. The total number of time steps $T$ required for complete the simulation was determined according to the simulation cutting velocity and the number of CA columns $m$ :

$$
T=v_{\mathrm{c}}^{-1} \cdot m
$$

The time to complete each simulation depends on the size of the CA. On an average office PC the time step duration for a matrix with dimensions $55 \times 150$ was on average 0.6 seconds for all simulations.

The simulation results are presented in the form of consecutive cutting fronts recorded during each simulation run. The single recording is obtained from matrix $\mathbf{B}$ by determining the border between different states as it is shown in Fig. 5.
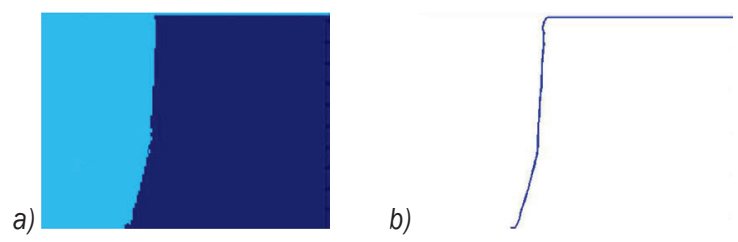

Fig. 5. a) the image of matrix $B$; and b) the border between different states

\section{EXPERIMENTAL WORK}

\subsection{Time Step Determination}

For simulation calibration purposes, the dimensions of the square cell were defined. If the focusing nozzle of $0.8 \mathrm{~mm}$ diameter is used, the size of the cell is equal to $0.8 / 3 \cong 0.267 \mathrm{~mm}$. This means the thickness of the workpiece in the simulation is $14.4 \mathrm{~mm}$.

Because the simulation has two unknown parameters $A_{\text {awj }}$ and a time step, it was decided to first fix the AWJ intensity and calibrate the simulation by matching the results for separation cut velocity. This is more pragmatic, as there is still no practical method to measure AWJ intensity. In order to perform the calibration the separation cut velocity for a particular AWJ machine setup, material and thickness has to be determined. This velocity is recorded when the AWJ just barely cuts through the workpiece. This velocity can also be calculated by using Zeng's equation [31] for calculating the depth of cut. If the operating parameters stated in Table 2 are used at the lowest cutting quality, the calculated separation cut is approximately $7 \mathrm{~mm} / \mathrm{s}$. The same parameters were used to practically perform such a cut on the OMAX 2652A AWJ machine. For practical purposes, the used workpiece thickness was $15 \mathrm{~mm}$.

In order to calibrate the CA model the parameters $A_{\text {awj }}$ and $t_{\mathrm{c}}$, which control the cutting velocity $v_{\mathrm{c}}$, have to be properly set in order for the separation cut to be obtained in simulation too. The AWJ intensity in the simulation was set to $A_{\text {awj }}=200$, which at the same 
time means that the calibration of jet parameters will also be performed.

By varying the $t_{\mathrm{c}}$ parameter in Eq. (2) and visually comparing the result to the real separation cut as presented in Fig. 6, the simulation separation cut velocity was found to be $v_{\mathrm{c}}=0.167$. In this case $t_{\mathrm{c}}$ was equal to 6 , meaning the AWJ moves forward one cell each 6 time steps. The simulation result is composed of consecutive recordings of the cutting fronts. For the sake of clarity, only every third front is shown.

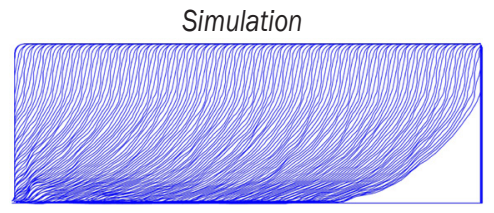

$v_{\mathrm{c}}=0.167$

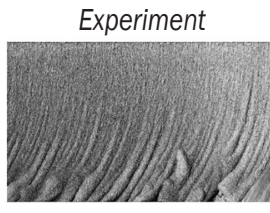

$v=7 \mathrm{~mm} / \mathrm{s}$
Fig. 6. Matching the separation cut velocity

Table 2. Separation cut process parameters

\begin{tabular}{lcc}
\hline Water pressure & {$[\mathrm{MPa}]$} & 300 \\
\hline Water orifice diameter & {$[\mathrm{mm}]$} & 0.25 \\
\hline Focusing tube diameter & {$[\mathrm{mm}]$} & 0.8 \\
\hline Abrasive mass flow rate & {$[\mathrm{kg} / \mathrm{min}]$} & 0.22 \\
\hline Abrasive type & & Garnet \# 80 \\
\hline Cutting velocity & {$[\mathrm{mm} / \mathrm{s}]$} & 7 \\
\hline Stand-off distance & {$[\mathrm{mm}]$} & 2 \\
\hline Material type (machinability number) & & AlMgSi1 (213) \\
\hline
\end{tabular}

Now the time step length can be determined. If the time needed to pass one cell the size of $0.267 \mathrm{~mm}$ with velocity of $7 \mathrm{~mm} / \mathrm{s}$ is equal to $0.0381 \mathrm{~s}$, then the time step size is equal to $0.0381 / 6 \cong 0.00635 \mathrm{~s}$.

\subsection{Trend Confirmation}

The further experimental work was focused on comparing the results with the simulation performance if 1) the cutting velocity is changed, 2) water pressure is changed and 3) different workpiece material is used. The additional parameters are presented in Table 3. The cut samples were then visually compared to the simulation results in order to compare trends.

Table 3. Additional process parameters used for the experiments

\begin{tabular}{lcc}
\hline Water pressure & {$[\mathrm{MPa}]$} & $200,250,300,350$ \\
\hline Cutting velocity & {$[\mathrm{mm} / \mathrm{s}]$} & $5,6,7,8,9$ \\
\hline $\begin{array}{l}\text { Material type (machinability } \\
\text { number) }\end{array}$ & AlMgSi1 (213), \\
& Steel St-37 (82), \\
& Soda lime glass (322) \\
\hline
\end{tabular}

\section{RESULTS}

\subsection{Variation of Velocity}

At first, the cutting velocity was varied according to Table 3 while all other parameters were fixed. In the experiment aluminium alloy AlMgSil was cut at a water pressure of $300 \mathrm{MPa}$. The simulation cutting velocity $v_{\mathrm{c}}$ can be calculated from the real velocity, cell size and time step by the following relation:

$$
v_{\mathrm{c}}=\frac{v}{\text { cell size }} \cdot \text { time step } .
$$

This relation defines the distance made by AWJ in the time of one time step, i.e. cell size per time step. The corresponding velocities are given in Table 4. The initial AWJ intensity at the source $A_{\text {awj }}$ was set to 200 as in the case of calibration.

The examples of simulation and experimental results for cutting velocities between $5 \mathrm{~mm} / \mathrm{s}$ and 9 $\mathrm{mm} / \mathrm{s}$ are shown in Fig. 7 .

Table 4. Simulation velocities

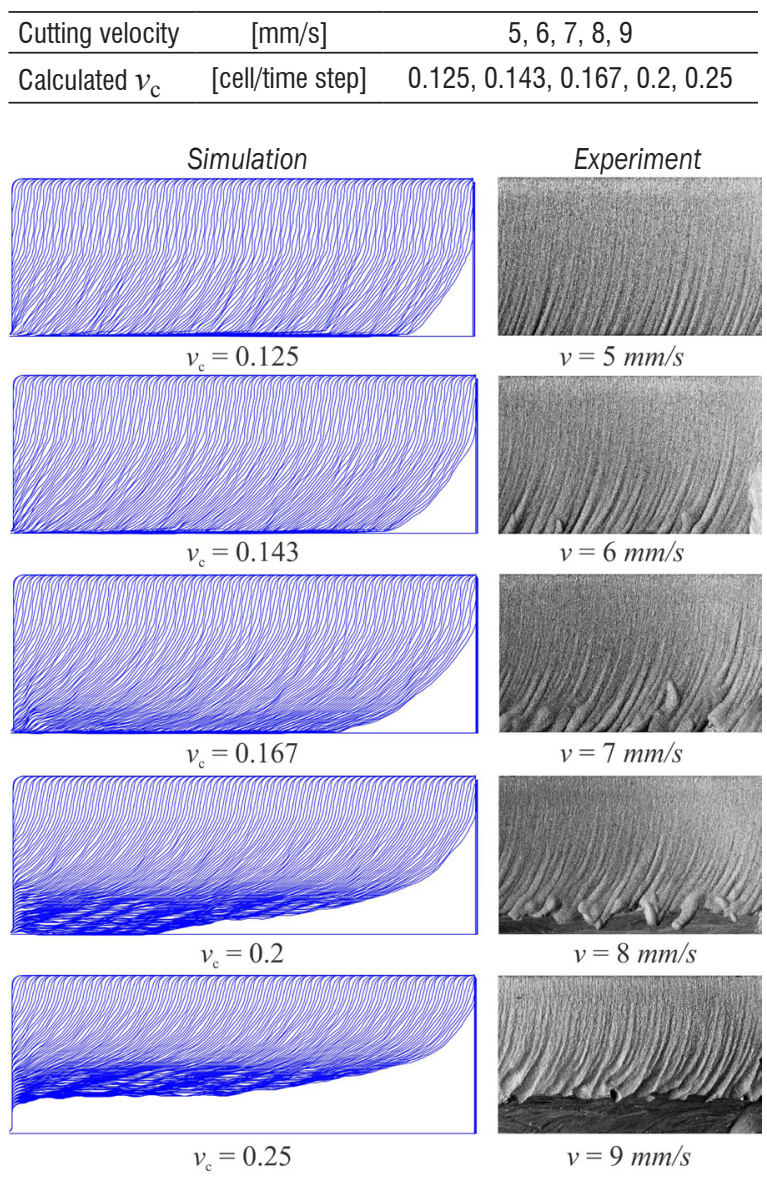

Fig. 7. The comparison of cutting velocities in a) simulation and b) experiment 


\subsection{AWJ Intensity and Material Resistance}

The simulation was tested for the change of initial AWJ intensity at the source of the jet and for the material resistance to the removal. The former corresponds to the change of water pressure (the abrasive parameters were left unchanged), whereas the latter corresponds to the material type. The simulation cutting velocity was fixed at $v_{\mathrm{c}}=0.167$, which corresponds to $\mathrm{v}=7$ $\mathrm{mm} / \mathrm{s}$ in the experiments.
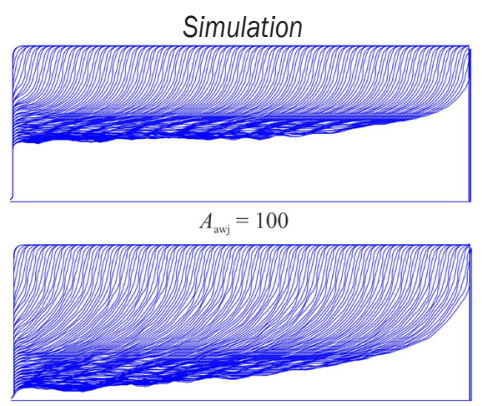

$A_{\text {axj }}=150$

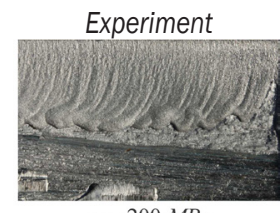

$p=200 \mathrm{MPa}$

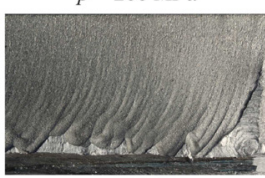

$p=250 \mathrm{MPa}$

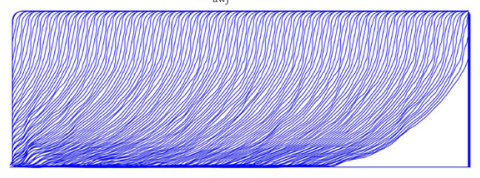

$A_{\text {axj }}=200$

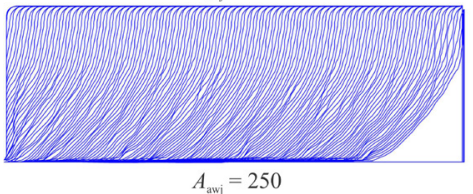

$A_{\text {axi }}=250$

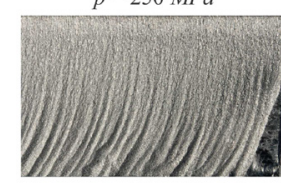

$p=300 \mathrm{MPa}$

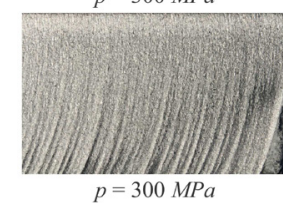

Fig. 8. The comparison of different AWJ intensities in a) simulation and $b$ ) experiment
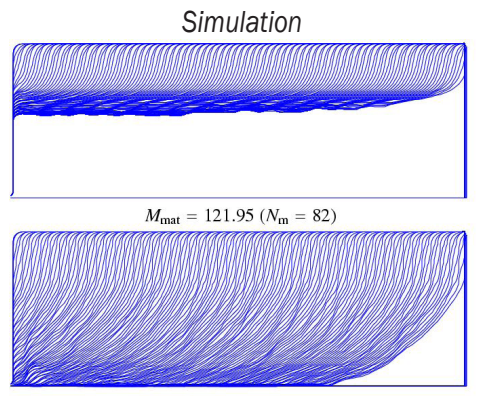

$M_{\text {mat }}=46.95\left(N_{\mathrm{m}}=213\right)$

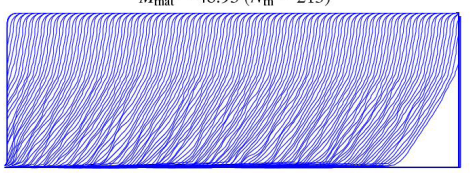

$M_{\text {mat }}=31.05\left(N_{\mathrm{m}}=322\right)$

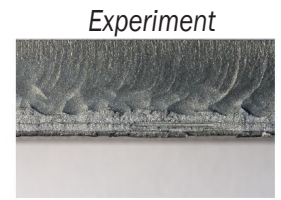

mild steel

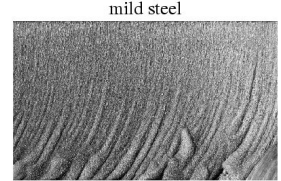

aluminium alloy

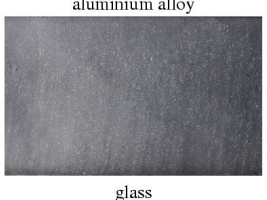

glass

Fig. 9. The comparison of cutting different materials in a) simulation and b) experiment

According to known facts [37], the final result during AWJ cutting is linearly proportional to the change in water pressure. Thus the AWJ intensity parameter was changed in equal increments according to Table 3 while in the simulation the parameter $A_{\text {awj }}$ was varied between value 100 and 250 based on the calibration run. The results for both the simulation and experiment are shown in Fig. 8 in the left and right columns, respectively.

The results of the simulation for three different materials according to Table 3 are presented for both the simulation and experiment in Fig. 9 in the left and right columns, respectively. Three different materials were chosen where aluminium alloy was taken as a reference from the calibration run while the other two materials have worse and better machinability than aluminium.

\section{DISCUSSION}

The simulation results show that the model is sound because by changing the input parameters, the curvature of the cutting front change is consistent with the response in the real process.

The presented model also considers redirection of AWJ flow. This allows it to also predict situations where the workpiece is not cut through due to higher cutting velocities. The results agree with those observed in the experiments.

With the previous model [26] this could not be simulated, as it was purely an energy based model which did not take into account the influence of abrasive slurry flow over the cutting front. In reality, when the cutting velocity for a certain material and a certain thickness is sufficiently high, the workpiece is not cut through even though it maintains significant energy to remove the material. This is due to the jet redirection at the bottom of the cut and not the AWJ intensity reduction [27].

The AWJ flow redirection at the cutting front depends on the interaction time between AWJ flow and workpiece material, AWJ intensity, AWJ flow direction and material type. While the first one is influenced by cutting velocity, which defines how much time the jet will have to remove a particular part of material, the later three deal with the material removal mechanism and thus define the material removal rate. If we want to focus on the cutting front development and its later influence on the cutting process, the proper material removal model has to be established. As solid particle erosion depends on the velocity of the abrasive grains, their impact angles and material type, all these parameters have been included into the CA model. This was done by calculating AWJ flow intensity in each cell, the direction of the flow, 
impact angle at the cutting front, flow redirection at the front, material resistance to erosion depending on the material type and the impact angle. It was shown that the relation between different materials defined by Zeng and Kim [31] can be used to simulate the cutting of a variety of materials. Also, it was shown that because of low impact angles at the cutting front, the relation between impact angle and material removal rate for ductile materials can on micro level be used for materials often regarded as brittle, e.g. glass. Compared to the previous models mentioned in the introduction, the major advantage of the CA method is it being a simplified and efficient model of AWJ cutting macro-mechanism, which can be used for further study of the process.

The presented 2D model on the other hand suffers from limitations connected to the striation generation mechanism, which is a three-dimensional problem and therefore has to be modelled in a three-dimensional space. This goes particularly for the occurrence of the so-called step, as the anomaly responsible for the striation formation can only be correctly obtained in $3 \mathrm{D}$, as this was already established in previous research [27].

\section{CONCLUSIONS}

A qualitative CA model for simulating the cutting with AWJ has been developed. It was shown that the CA approach can be successfully used to describe the AWJ cutting process. In order for the model to simulate the development of the cutting front by varying process parameters, such as cutting velocity, AWJ intensity and material type, the material removal and AWJ flow mechanisms have to be properly defined. The material removal model encompasses the solid particle erosion process and its parameters while the AWJ flow model considers both energy potential and the direction in which it moves. Therefore, the simulation results like flow redirection, not cutting through the workpiece and cutting of different materials are possible to obtain.

The presented model is a stepping stone towards modelling the striation generation mechanism in a three-dimensional space. Although the influence of the cutting front surface shape on the striation formation was partially confirmed in the presented 2D model, this will be fully possible in 3D. Thus, the CA model should be expanded into the third dimension, which requires adding additional equations for the third dimension.

\section{ACKNOWLEDGMENTS}

This work was supported by the Slovenian Research Agency (ARRS).

\section{REFERENCES}

[1] Levy, A.V. (1995). Solid Particle Erosion and Erosion-Corrosion of Materials. ASM International, Materials Park.

[2] Fukunishi, Y., Kobayashi, R. and Uchida, K. (1995). Numerical simulation of striation formation on water jet cutting. Proceedings of the $8^{\text {th }}$ Water Jet Conference, vol. 2, WJTA, Houston, p. 657-670.

[3] Sawamura, T., Fukunishi, Y. (1997). Three dimensional model for waterjet cutting simulation. Proceedings of the $9^{\text {th }}$ Water Jet Conference, vol. 1, WJTA, Dearborn, p. 133-144.

[4] Bitter, J.G.A. (1963). A study of erosion phenomena - Part I. Wear, vol. 6, p. 5-21, D0l:10.1016/0043-1648(63)90003-6.

[5] Bitter, J.G.A. (1963). A study of erosion phenomena - Part II. Wear, vol. 6, p. 169-190, Dol:10.1016/0043-1648(63)900735.

[6] Vikram, G., Babu, N.R. (2001). Modelling and simulation of abrasive water jet cut surface topography. Proceedings of the 11th Water Jet Conference. vol. 1, WJTA, Minneapolis, p. 1328.

[7] El Tobgy, M., Ng, E.G., Elbestawi, M.A. (2005). Modelling of abrasive waterjet machining: a new approach. CIRP Annals - Manufacturing Technology, vol. 54, no. 1, p. 285-288, DOl:10.1016/S0007-8506(07)60104-8.

[8] Yong, Z., Kovacevic, R. (1997). 3D simulation of macro and micro characteristics for AWJ machining. Proceedings of the $9^{\text {th }}$ Water Jet Conference, vol. 1, WJTA, Dearborn, p. 15-28.

[9] Ditzinger, T., Friedrich, R., Henning, A., Radons, G. (1999). Non-linear dynamics in modelling of cutting edge geometry. Proceedings of the 10th Water Jet Conference, vol. 1, WJTA, Houston, p. 15-32.

[10] Lebar, A. (2002). Modelling of Abrasive Water Jet Cutting Process. PhD thesis, University of Ljubljana, Ljubljana.

[11] Lebar, A., Junkar, M. (2003). Simulation of abrasive waterjet machining based on unit event features. Proceedings of the Institution of Mechanical Engineers, Part B: Journal of Engineering Manufacture, vol. 217, p. 699-703, DOI:10.1243/095440503322011425.

[12] Deam, R.T., Lemma, E., Ahmed, D.H. (2004). Modelling of the abrasive water jet cutting process. Wear, vol. 257, no. 9-10, p. 877-891, D0I:10.1016/j.wear.2004.04.002.

[13] Zaki, M., Corre, C., Kuszla, P., Chinesta, F. (2008). Numerical simulation of the abrasive waterjet (AWJ) machining: multi-fluid solver validation and material removal model presentation. International Journal Material Forming, vol. 1, p. 1403-1406, DOl:10.1007/s12289-008-0127-8.

[14] Jianming, W., Na, G., Wenjun, G. (2010). Abrasive waterjet machining simulation by SPH method. International Journal of Advanced Manufacturing Technology, vol. 50, no. 1-4, p. 227234, D0I:10.1007/s00170-010-2521-x.

[15] Wenjun, G., Jianming, W., Na, G. (2011). Numerical simulation for abrasive water jet machining based on ALE algorithm. 
International Journal of Advanced Manufacturing Technology, vol. 53, no. 1-4, p. 247-253, D0l:10.1007/s00170-010-2836-7.

[16] Benyoussef, A., El Hafid Allah, N., El Kenz, A., Ez-Zaharouy, H., Loulidi, M. (2003). Dynamics of HIV infection on 2D cellular automata. Physica A: Statistical Mechanics and its Applications, vol. 322, p. 506-520, Dol:10.1016/S03784371(02)01915-5.

[17] Alarcon, T., Byrneb, H.M., Maini, P.K. (2003). A cellular automaton model for tumour growth in inhomogeneous environment. Journal of Theoretical Biology, vol. 225, p. 257 274, DOI:10.1016/S0022-5193(03)00244-3.

[18] Viher, B., Dobnikar, A., Zazula, D. (1998). Cellular automata and follicle recognition problem and possibilities of using cellular automata for image recognition purposes. International Journal Medical Informatics, vol. 49, no. 2, p. 231-241, D0I:10.1016/S1386-5056(98)00042-2.

[19] Dobnikar, A., Vavpotic S., Likar, A. (2002). Dynamic systems modeling with stochastic cellular automata (evolutionary versus stochastic correlation approach). Journal of Computing and Information Technology - CIT, vol. 10, no. 4, p. 251-259, D0l:10.2498/cit.2002.04.01.

[20] Maerivoet, S., De Moor, B. (2005). Cellular automata models of road traffic. Physics Reports, vol. 419, no. 1, p. 1-64, D0I:10.1016/j.physrep.2005.08.005.

[21] Zhang, L., Wang, Y.M., Zhang, C.B., Wang, S.Q., Ye, H.Q. (2003). A cellular automaton model of transformation from austenite to ferrite in low carbon steels. Modelling and Simulation in Material Science and Engineering, vol. 11, no. 5, p. 791-802, Dol:10.1088/0965-0393/11/5/306.

[22] Karafyllidis, I., Thanailakis, A. (1995). Simulation of the twodimensional photoresist etching process in integrated circuit fabrication using cellular automata. Modelling and Simulation in Material Science and Engineering, vol. 3, no. 5, p. 629-642, DOI:10.1088/0965-0393/3/5/004.

[23] Wolf-Gladrow, D.A. (2000). Lattice-gas Cellular Automata and Lattice Boltzmann Models: an Introduction. Springer, Berlin, D0I:10.1007/b72010.

[24] D’Ambrosio, D., Di Gregorio, S., Gabriele, S., Gaudio, R. (2001). A cellular automata model for soil erosion by water. Physics and Chemistry of the Earth, Part B, vol. 26, no. 1, p. 33-39, DOI:10.1016/S1464-1909(01)85011-5.
[25] Murray, A.B., Paola, C. (1994). A cellular model of braided rivers. Nature, vol. 371, p. 54-57, D0l:10.1038/371054a0.

[26] Orbanic, H., Junkar, M. (2004). Simulation of abrasive water jet cutting process: Part 2. Cellular automata approach. Modelling and Simulation in Material Science Engineering, vol. 12, p. 1171-1184, D0l:10.1088/0965-0393/12/6/011.

[27] Orbanic, H., Junkar, M. (2008). Analysis of striation formation mechanism in abrasive water jet cutting. Wear, vol. 265, no. 5-6, p. 821-830, D0l:10.1016/j.wear.2008.01.018.

[28] Chopard, B., Droz, M. (1998). Cellular Automata Modelling of Physical Systems. Cambridge University Press, D0l:10.1017/ CB09780511549755.

[29] Wolfram, S. (1994). Cellular Automata and Complexity. Addison-Wesley, Reading.

[30] Zeng, J., Kim, T.J. (1992). Development of an abrasive waterjet kerf cutting model for brittle materials. Proceedings of $11^{\text {th }}$ International Conference on Jet Cutting Technology, St. Andrews, Kluwer Academic Publishers, p. 483-501, Dol:10.1007/978-94-011-2678-6_33.

[31] Zeng, J., Kim, T.J. (1995). Machinability of engineering materials in abrasive water jet machining. International Journal of Water Jet Technology, vol. 2, no. 2, p. 103-110.

[32] OMAX Intelli-MAX Premium (2009) OMAX Make for Windows, Version: 14.0.

[33] Finnie, I. (1995). Some reflections on the past and future of erosion. Wear, vol. 186-187, p. 1-10, D0I:10.1016/00431648(95)07188-1.

[34] Ballout, Y., Mathis, J.A., Talia, J.E. (1996). Solid particle erosion mechanism in glass. Wear, vol. 196, no. 1-2, p. 263269, D0I:10.1016/0043-1648(96)06922-0.

[35] Wensink, H., Elwenspoek, M.C. (2002). A closer look at the ductile-brittle transition in solid particle erosion. Wear, vol. 253, no. 9-10, p. 1035-1043, DOI:10.1016/S00431648(02)00223-5.

[36] Baker, M.J. (2011). Euclidian Space, from http://www. euclideanspace.com/maths/geometry/affine/reflection/ index.htm accessed on 2011-10-06.

[37] Momber, A.W., Kovacevic, R. (1998). Principles of Abrasive Water Jet Machining, Springer-Verlag, London, DOI:10.1007/978-1-4471-1572-4. 